\title{
Late sequelae of pulmonary tuberculosis treated by thoracoplasty
}

\author{
M S PHILLIPS, W J M KINNEAR, J M SHNEERSON
}

From the Chest Unit, Papworth Hospital, Cambridge

ABSTRACT With the help of information provided by the Office of Population, Censuses and Surveys the survival up to 1 July 1985 of the 171 patients treated for pulmonary tuberculosis by thoracoplasty at Papworth from 1951 to 1953 was determined. Thirteen (8\%) could not be traced, $65(38 \%)$ had died, and $93(54 \%)$ were alive. For those who were traced the survival at 10, 20, and 30 years from the date of operation was $93 \%, 79 \%$, and $65 \%$. This represents a significantly greater mortality rate than that predicted from the Registrar General's review of deaths in England and Wales (1841-1984). Nineteen patients died from cardiorespiratory failure. Eight of the survivors are known to have developed respiratory failure, five having enjoyed apparently good health before this was precipitated by intercurrent illness or drugs. A stepwise logistic regression analysis using information from the 124 patients for whom full details were available showed significant associations between the development of cardiorespiratory or respiratory failure and a preoperative contralateral artificial pneumothorax, older age at operation, the presence of cavities before operation, and male sex. In a questionnaire 50 of the survivors (57\% of those who replied) reported cough, 45 $(51 \%)$ breathlessness, $41(47 \%)$ wheeze, and $24(27 \%)$ ankle swelling. Nineteen $(22 \%)$ smoke and the same number now attend a chest clinic. Many patients treated for tuberculosis by thoracoplasty have respiratory symptoms and some are at risk of respiratory failure. There are grounds for considering that they should be reviewed periodically by a chest physician.

Thoracoplasty was an important form of collapse therapy for pulmonary tuberculosis before effective antituberculous chemotherapy was established. ${ }^{1}$ The number of patients treated in this way is not known. At least 3000 thoracoplasties are, however, known to have been performed in the United Kingdom from 1 April 1953 to 31 March $1954 .^{2}$ Thirty seven thoracoplasties were performed at Papworth Hospital in this period, representing $10 \%$ of the total (359) carried out at this hospital in the whole decade, 1951-60. If Papworth is representative of the country as a whole, some 30000 thoracoplasties will have been performed in the United Kingdom between 1951 and 1960.

Most of the patients treated at this time were alive and well a few years after operation, ${ }^{34}$ but very little is known of how they have fared in recent years. Perhaps recurrent tuberculosis and the adverse effects on respiratory function of both disease and treatment have already taken a heavy toll among these early

Address for reprint requests: Dr MS Phillips, Papworth Hospital, Papworth Everard, Cambridge CB3 8RE.

Accepted 9 December 1986 survivors, but this information is not available. Undoubtedly some have survived, for they are now seen either with intercurrent illness or with respiratory or cardiac failure, which often seems to be of sudden onset after many years of apparently good health. ${ }^{5}$ If many patients have indeed survived to the present day adequate provision for the appropriate treatment of such episodes of respiratory failure should now be made. This may include the use of devices to assist ventilation both in hospital and at home. ${ }^{6}$

The aims of this study were: $(a)$ to discover how many of the patients treated by thoracoplasty at this hospital in 1951-3 had died by 1 July 1985; (b) to calculate the proportion in whom respiratory failure is known to have occurred and to identify factors from the time of operation that may have predisposed to its development; $(c)$ to gain some knowledge of the health, lifestyle, and provision for health care of the survivors.

\section{Methods}

The number of patients with pulmonary tuberculosis treated by thoracoplasty in Papworth Hospital, 
Cambridge, from 1 January 1951 to 31 December 1953 was obtained from the theatre operating book. Further information was obtained from the original hospital case notes, where available. Then details of all the patients were sent to the Office of Population, Censuses, and Surveys (OPCS).

\section{MORTALITY}

From the replies the survival rate of the patients over 30 years from the date of operation was calculated. A life table for the patients from the year of operation was constructed from the percentage survival to the end of each year of those who could be traced. Allowance was made for patients who emigrated (and who therefore survived to the year of emigration) whose ultimate fate was not known. The hypothetical life table from the year of operation of a "control" group matched for age and sex with all the patients, traced and untraced, was calculated from the mortality statistics serial tables contained in the reviews of the Registrar General on deaths in England and Wales, 1841-1984. ${ }^{7}$ The survival of the two groups was compared by means of the $\log$ rank test. ${ }^{8}$

\section{CARDIORESPIRATORY FAILURE}

For those patients who died in England or Wales before 1 July 1985 the OPCS supplied a copy of the death certificate, from which the date and cause of death were obtained. The causes were divided into three categories: tuberculosis, cardiorespiratory failure, and others. The criterion for inclusion within the category cardiorespiratory failure was either cor pulmonale or respiratory failure stated as the cause of death or death shown to be due to a respiratory condition, with "old pulmonary tuberculosis" named as a contributing factor.

For those patients who survived to 1 July 1985 the OPCS identified the family practitioner committee employing the patient's general practitioner. A questionnaire was sent to each general practitioner asking if his patient had been admitted to hospital within the past five years because of respiratory or cardiac disease. If there had been an admission to hospital the case records were sought from the admitting physician. The clinical features of each admission were noted together with any results of respiratory function, particularly arterial blood gas analysis. The presence of respiratory failure was defined by a $\mathrm{PaO}_{2}$ of less than $8.0 \mathrm{kPa}$ or a $\mathrm{PaCO}_{2}$ of greater than $6.5 \mathrm{kPa}$ while the patient was breathing room air.

Information on age at operation, sex, and side of operation was available for all patients from the theatre operating book. The following were recorded for those patients whose original hospital notes were available: length of preoperative history of tuberculosis; bilateral or unilateral disease; cavitation present at the time of operation; previous ipsilateral artificial pneumothorax; previous contralateral $\stackrel{\vec{\rho}}{\vec{g}}$ artificial pneumothorax; and number of ribs resected. A stepwise logistic regression analysis using $\frac{}{}$ BMDPLR $^{9}$ was performed to determine which of these factors were significantly associated with the $\mathbb{\otimes}$ subsequent development of respiratory or cardiorespiratory failure. A $5 \%$ level of significance was set ${ }^{\mathrm{S}}$ for inclusion of a variable in the regression model.

HEALTH, LIFESTYLE, AND HEALTH CARE The questionnaire sent to the general practitioner also asked whether he had been consulted by the patient because of breathlessness within the previous five $\stackrel{\mathrm{N}}{\mathrm{o}}$ years, whether the patient was chronically breathless, and whether the patient had ever developed ankle $\vec{r}$ oedema. It asked whether the patient had been pre- ? scribed diuretics, digoxin, bronchodilators (inhaled or oral), corticosteroids (inhaled or oral), or domicil- $c$ iary oxygen. Information about illnesses, including $\frac{\bar{\sigma}}{\bar{\Phi}}$ further tuberculosis and its treatment, was sought. $\vec{D}$ Finally details of the patient's attendance at a chest $\stackrel{\mathscr{O}}{\mathscr{N}}$ clinic were requested.

A second questionnaire was sent to each surviving patient. It inquired about breathlessness, cough, sputum, wheeze, pain at the site of the thoracoplasty scar, $\bar{O}$ and ankle swelling. The possibility of nocturnal hypo- 응 ventilation and early morning hypercapnia was ex- $₫$ plored by questions about interrupted and poor $\overrightarrow{\bar{O}}$ quality sleep at night, snoring, early morning head- 3 ache, early morning confusion, daytime somnolence, and inability to concentrate. Details of smoking hab-무․ its were requested. Men were asked whether they had been able to return to the same work after the tho-음 racoplasty. Women were asked whether they could $\stackrel{\times}{\times}$ cope with their housework. Both sexes were asked about marriage and children, and whether the scar and deformity produced by the operation had caused 0 them embarrassment. Finally they were asked if they would choose to be seen regularly at a chest clinic. 을

Comparison was made, using a $\chi^{2}$ test, of the symp- $\rightarrow$ toms reported by those patients still attending a chest clinic and those who were not, and of the symptoms reported by patients who smoked and those who did not.

\section{Results}

One hundred and seventy one patients (95 women, $76 \nsubseteq$ men; mean age 31.8 (SD 8.4) years, range $16-54 \stackrel{?}{\circ}$ years) were treated by thoracoplasty at Papworth ${ }^{\circ}$ Hospital from 1951 to 1953 . In seven this was carried $\stackrel{\vec{\Phi}}{\vec{D}}$ out bilaterally. The standard procedure during this time was a partial paravertebral thoracoplasty with $\stackrel{\varnothing}{\unrhd}$ extrafascial apicolysis. The end result was accomplished by a two or three stage operation with partial 0 
removal of four to nine ribs, beginning with the first three ribs. Three surgeons between them performed all the operations, which were carried out under general anaesthesia. In seven patients thoracoplasty was carried out at the same time as or shortly after ipsilateral pulmonary resection (pneumonectomy in five cases and upper lobectomy in two). The original hospital notes were available for $141(82 \%)$ of the patients.

\section{MORTALITY}

Thirteen patients $(8 \%)$ could not be traced by the OPCS. Four of them had emigrated; the year of emigration was provided. Of the remaining $158,65(38 \%)$ had died by 1 July 1985 and $93(54 \%)$ were alive. The survival at 10,20, and 30 years from the date of operation was $93 \%, 79 \%$, and $65 \%$. Life tables for the patients and "controls" are shown in figure 1. The excess mortality among the patients is significant $\left(\chi^{2}\right.$ $=4.6 ; \mathrm{df} 1 ; \mathrm{p}<0.05)$. Sixty three per cent of those traced survived to the end of 1984, compared with $74 \%$ for the "control" group. As expected, age has an important influence on mortality. Forty two of the 65 $(65 \%)$ who would have been 65 years or more on 1 July 1985 had died, as opposed to 23 of the $93(25 \%)$ who would have been less than 65 years. The mean

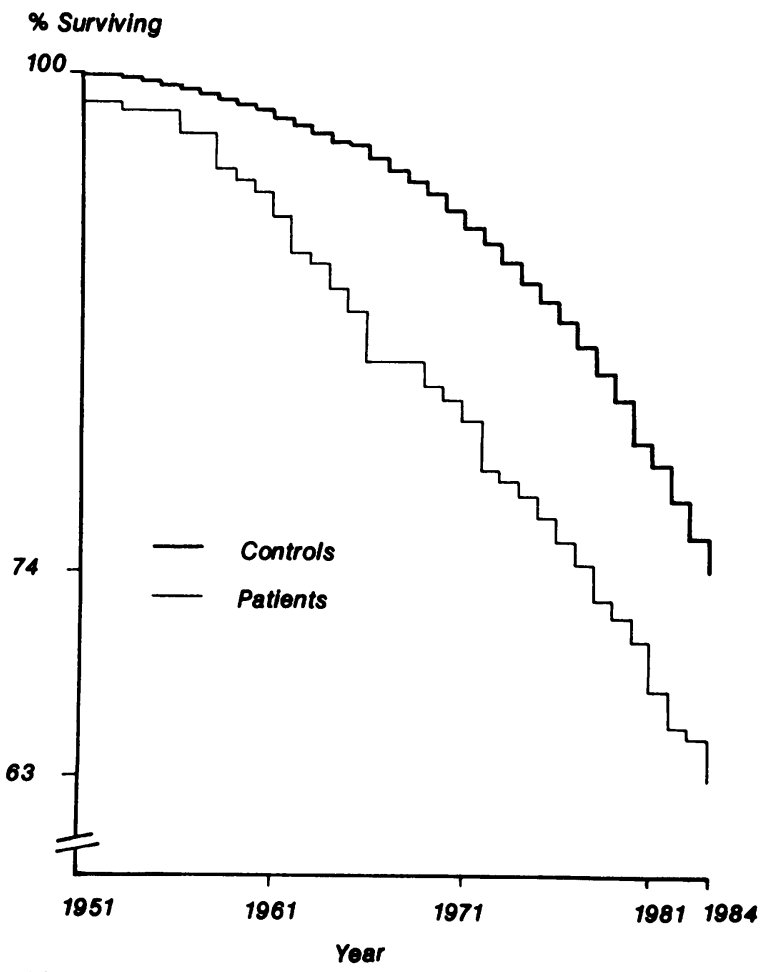

Fig 1 Life tables for the patients and "controls." age of the 93 surviving patients on 1 July 1985 was $61 \cdot 2$ (SD 6.4) years, range $47-82$ years; $66(71 \%)$ were less than 65 .

\section{CARDIORESPIRATORY FAILURE}

The causes of death are shown in table 1 . Nineteen deaths were due to cardiorespiratory failure, $31 \%$ of those for which a cause was known. The proportion of deaths due to cardiorespiratory failure in each decade was fairly constant-1951-60 33\%; 1961-70 $28 \%$; 1971-80 37\%; 1981-5 27\%. The percentage of patients who, having survived to the beginning of a decade, then die from cardiorespiratory failure in that decade has steadily increased (fig 2). The figure for 1981-90 is based on the deaths that have occurred in the 4.5 years from 1 January 1981 .

Thirteen of the survivors had been admitted to hospital within the previous five years, seven as emergencies because of respiratory failure. All seven were severely hypoxic (mean $\mathrm{PaO}_{2} 4 \cdot 1 \mathrm{kPa}$ ) and hypercapnic (mean $\mathrm{PaCO}_{2} 8.6 \mathrm{kPa}$ ). A remediable precipitating factor was identified in five cases-pneumonia (2), left ventricular failure (1), perforated gastric ulcer (1), prescription of a hypnotic drug (1). All five felt that they had been leading normal lives until an abrupt illness of well defined onset. The duration of their symptoms had been from two days to four weeks. Early morning headache was prominent in three. Four of the seven needed mechanical ventilation. One other survivor was found to have hypercapnic respiratory failure $\left(\mathrm{PaCO}_{2} 6.6 \mathrm{kPa}\right)$ during an elective admission for investigation of breathlessness. Five of the seven are known to have required readmission, two before 1 July 1985 and three subsequently. In each case details of the first admission were taken. The mean age of the eight patients with respiratory failure at the time of their first admission was $62 \cdot 5$ years.

Table 1 Causes of death and ages at death

\begin{tabular}{lcl}
\hline Cause & No & Age $(y)($ mean $(S D))$ \\
\hline $\begin{array}{l}\text { Tuberculosis } \\
\text { Miliary }\end{array}$ & 4 & $43 \cdot 0(3 \cdot 7)$ \\
$\begin{array}{l}\text { Pulmonary } \\
\text { Cardiorespiratory failure }\end{array}$ & $(1)$ & \\
$\quad \begin{array}{l}\text { Cor pulmonale } \\
\text { Congestive cardiac failure or } \\
\text { pulmonary hypertension }\end{array}$ & 19 & $55 \cdot 8(12 \cdot 6)$ \\
$\quad$ due to old pulmonary & & \\
$\quad$ tuberculosis and & & \\
$\quad$ thoracoplasty & $(4)$ & \\
$\begin{array}{l}\text { Respiratory failure } \\
\text { Bronchitis or pneumonia } \\
\text { complicating old pulmonary } \\
\quad \text { tuberculosis and } \\
\text { thoracoplasty }\end{array}$ & $(2)$ & \\
$\begin{array}{l}\text { Other causes } \\
\text { Cause unknown }\end{array}$ & $(5)$ & \\
Total & 38 & $58 \cdot 8(11 \cdot 6)$ \\
& 4 & $48 \cdot 0(11 \cdot 9)$ \\
\hline
\end{tabular}




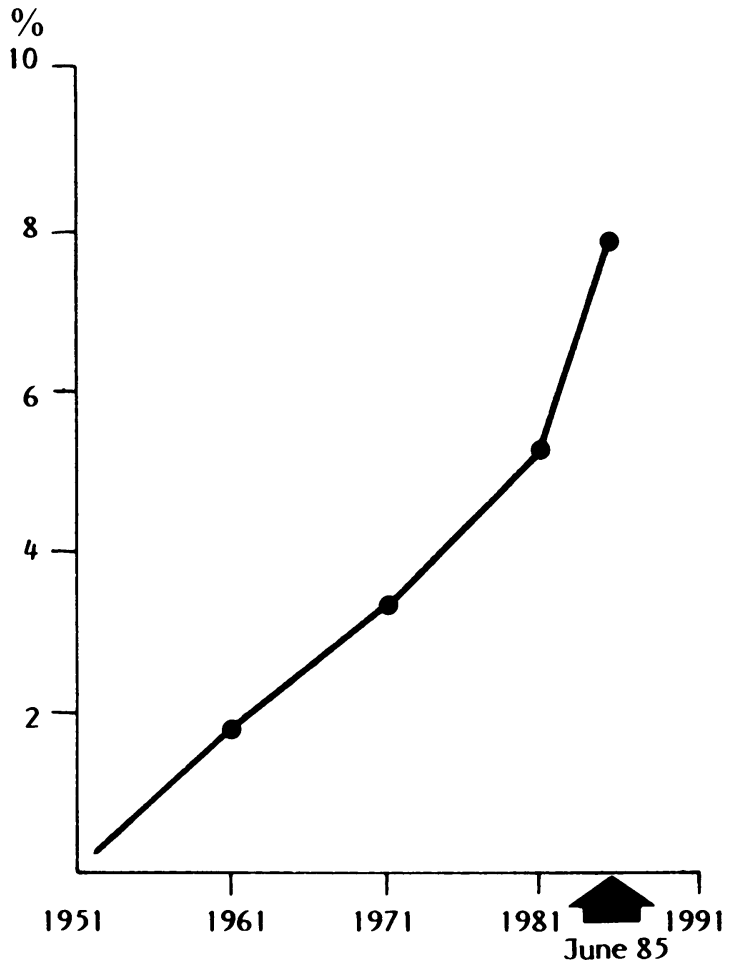

Fig 2 Mortality from cardiorespiratory failure by decade since 1951.

Complete data were available for 124 patients (24 of whom developed respiratory or cardiorespiratory failure), allowing them to be included in the stepwise logistic regression analysis. The results are shown in table 2. The most important association with the development of respiratory or cardiorespiratory failure was a previous contralateral artificial pneumothorax. Other significant $(\mathrm{p}<0.05)$ independent associations were older age at operation, presence of cavities at the time of operation, and male sex.

None of the seven patients treated by pulmonary resection and supplementary thoracoplasty developed respiratory or cardiorespiratory failure.

HEALTH, LIFESTYLE, AND HEALTH CARE

Eighty eight general practitioners $(94 \%)$ returned a completed questionnaire. Eighty eight patients also replied, including the five whose general practitioners had not, so that some information was available for all 93 surviving patients. A recurrence of pulmonary tuberculosis since 1960 was reported for four patients. Three more have developed extrapulmonary disease, all since 1978, while five others have received chemoprophylaxis. Twenty nine patients had consulted their general practitioner within the past five years because of breathlessness and 18 of them were considered to
Table 2 Stepwise logistic regression analysis for factors associated with the development of respiratory or cardiorespiratory failure

\begin{tabular}{llll}
\hline Factor & Coefficient & $\begin{array}{l}\text { Standard } \\
\text { error }\end{array}$ & $p$ \\
\hline $\begin{array}{l}\text { Contralateral artificial } \\
\text { pneumothorax }\end{array}$ & 1.11 & 0.31 & 0.0001 \\
$\begin{array}{l}\text { Age at operation } \\
\text { Presence of cavities at }\end{array}$ & 0.12 & 0.04 & 0.0004 \\
$\quad$ operation & 0.77 & 0.38 & 0.0215 \\
Male sex & 0.51 & 0.28 & 0.0379 \\
\hline
\end{tabular}

be chronically breathless. Ten general practitioners reported that their patients had developed ankle $\mathrm{N}$ oedema. The symptoms reported by the patients are $\sigma$ shown in table 3 . There were considerable differences between patient and doctor in the replies concerning 0 breathlessness and ankle swelling. Eleven of the 29 윽 who consulted their general practitioner because of $\vec{c}$ breathlessness reported no breathlessness. On the other hand the general practitioners were unaware of $\overparen{\Phi}$ some degree of breathlessness reported by 27 of their $\vec{\theta}$ patients, and 24 patients reported ankle swelling.

Ten patients were treated with bronchodilators (five inhaled, one oral, four combined). Six received inhaled corticosteroids, two oral corticosteroids, four digoxin, and seven diuretics. Four have domiciliary oxygen. Seventy two $(82 \%)$ received no treatment to $\mathbb{D}$ the knowledge of their general practitioner.

Thirty five patients $(40 \%)$ had never smoked. Thirty four (39\%) were ex-smokers and $19(22 \%)$ still smoked. Surprisingly, the only significant difference

Table 3 Replies from questionnaires returned by 88 of 93 traced surviving patients

\begin{tabular}{|c|c|c|}
\hline & No & $\%$ \\
\hline \multicolumn{3}{|l|}{ Breathlessness } \\
\hline Present to some degree & 45 & 51 \\
\hline Unable to hurry & 41 & 47 \\
\hline \multicolumn{3}{|l|}{$\begin{array}{l}\text { Not able to keep pace with others of } \\
\text { the same age while walking on }\end{array}$} \\
\hline level ground & 28 & 32 \\
\hline \multicolumn{3}{|l|}{ Not able to walk as far as would like } \\
\hline \multicolumn{3}{|l|}{ Unable to walk 100 yards $(91 \mathrm{~m})$ up } \\
\hline a gentle incline & 19 & 22 \\
\hline $\begin{array}{l}\text { Unable to climb a flight of } 12 \text { stairs } \\
\text { Breathlessness not reported to GP }\end{array}$ & 12 & $\begin{array}{l}14 \\
30\end{array}$ \\
\hline \\
\hline & 50 & 57 \\
\hline Throughout the year & 11 & 13 \\
\hline \multirow{2}{*}{\multicolumn{3}{|c|}{$\begin{array}{l}\text { For } 3-12 \text { months of each year } \\
\text { For less than } 3 \text { months of each year }\end{array}$}} \\
\hline & & \\
\hline Wheeze & 41 & 47 \\
\hline Haemoptysis within the past 10 years & 6 & 7 \\
\hline $\begin{array}{l}\text { Pain at the site of the operation scar } \\
\text { Ankle swelling }\end{array}$ & 26 & 30 \\
\hline \multicolumn{3}{|l|}{$\begin{array}{l}\text { Ankle swelling } \\
\text { Five or more symptoms* suggesting }\end{array}$} \\
\hline $\begin{array}{l}\text { nocturnal hypoventilation } \\
\text { No symptoms at all }\end{array}$ & 3 & 3 \\
\hline No symptoms at all & 12 & 14 \\
\hline \multicolumn{3}{|l|}{ *See under "Methods." } \\
\hline
\end{tabular}


$(\mathrm{p}<0.05)$ in symptoms between the 19 patients who smoked and the 69 who did not was less breathlessness among those who smoke.

After their thoracoplasty 22 of the 33 men who replied had been able to return to work similar to that done previously. The other 11 took lighter jobs. Six of the 53 women who replied reported that they had difficulty coping with their housework after the operation.

Thirteen of the 19 men and 17 of the 25 women who were unmarried at the time of operation married subsequently. Twenty two of the 26 married men and 33 of the 47 married women had children. For 14 men and 19 women at least one child was born after the operation. The scar and deformity caused by the operation had caused embarrassment to nine $(28 \%)$ men and $20(36 \%)$ women.

Nineteen patients $(22 \%)$ still attended a chest clinic. Replies from the others indicated that 63 had been discharged; three had allowed their attendance to lapse while three gave no reason. Cough and breathlessness of some degree were significantly more frequent $(p<0.05)$ among those who were still attending. Fifty two of the 88 patients $(59 \%)$ would choose to attend a chest clinic at regular intervals, 30 $(34 \%)$ would not, and six $(7 \%)$ were ambivalent about this.

\section{Discussion}

These survival figures may cause surprise, given the guarded prognosis that could be given to patients with pulmonary tuberculosis in the days before chemotherapy. ${ }^{10}$ The mortality rate for the group we studied is significantly greater than that derived for an age and sex matched population from the Registrar General's mortality figures. Tuberculosis itself does not seem to account for this excess mortality. Indeed, our findings suggest that thoracoplasty met with considerable success in controlling and curing the disease (though we do not know what influence any antituberculous chemotherapy given to our patients in the postoperative years up to 1960 may have had). It has long been recognised that respiratory ${ }^{11}$ and cardiac $^{12}$ failure may occur after thoracoplasty, and in our study most of the excess mortality is due to cardiorespiratory failure.

Cardiorespiratory failure is difficult to define satisfactorily for a retrospective survey such as this and we recognise that our definition may not be universally accepted. Furthermore, death certificates may contain inaccuracies. ${ }^{13}$ Nevertheless, we believe that if our criterion was satisfied the patient was very likely to have respiratory failure, or at least severe impairment of respiratory function sufficient to cause respiratory failure during an intercurrent illness, at the time of death.

Our methods may have left undetected some patients who did develop respiratory failure. In particular, any who died from other causes and whose death certificate did not mention their respiratory failure will have been missed. Moreover, surviving patients who have or have had respiratory failure but who have not required admission to hospital within the past five years will not be included. Our overall figure of 27 with respiratory or cardiorespiratory failure out of $158(17 \%)$ is best regarded as a minimum and may well underestimate the true figure.

Overall mortality was, as expected, greater in those who were older at operation. Furthermore, the percentage mortality from cardiorespiratory failure by decade since 1951 has steadily increased as the patients have got older. This suggests that more of the 93 survivors, of whom $71 \%$ were less than 65 years old on 1 July 1985, are likely to develop cardiorespiratory failure within the next decade.

Seven of the eight surviving patients with respiratory failure have been near to death with severe hypoxaemia and hypercapnia. The striking clinical feature is that five of them had been without symptoms and were leading apparently normal lives until a few days or weeks before their admission. Sawicka $e t$ $a l^{5}$ noted this in five of their 10 patients who needed ventilatory assistance for respiratory failure after thoracoplasty. It is worth emphasising that the admission of one of our patients was precipitated by the prescription of a drug causing respiratory depression. Patients with a thoracoplasty who are chronically hypercapnic may be particularly susceptible to the effects of drugs that depress ventilation. Early morning headache, reported by three of our patients, should raise the possibility of nocturnal hypercapnia.

Although some things likely to influence the development of respiratory failure, such as smoking and the inevitable postoperative scoliosis, ${ }^{14}$ were not investigated, certain factors from the time of operation were linked with the development of cardiorespiratory or respiratory failure and may be useful in identifying patients for whom this is a particular risk. The factor we found to correlate best with subsequent cardiorespiratory or respiratory failure was a previous contralateral artificial pneumothorax. This presumably relates to the high incidence of pleural thickening and fibrosis after artificial pneumothorax, which is often considerable and associated with a severe restrictive ventilatory defect. ${ }^{15}$ In patients with a thoracoplasty limitation of expansion of the contralateral lung may be the chief factor determining the development of alveolar hypoventilation and respiratory failure. Older age at operation may reflect more extensive disease $^{2}$ as well as any effect of aging itself. The presence of cavities at the time of operation is 
also likely to reflect more extensive disease and greater residual pulmonary fibrosis. Greater cigarette smoking among the men, before and after the operation, may contribute to their increased likelihood of respiratory failure.

Gaensler et $a l^{11}$ showed that the postoperative decrease in vital capacity after thoracoplasty was directly proportional to the number of ribs resected. Little $^{16}$ found that the postoperative falls in maximum breathing capacity and $\mathrm{FEV}_{1}$ were also directly related to the number of ribs resected. Gaensler and Strieder ${ }^{17}$ showed that a very low postoperative vital capacity was a feature of pneumonectomy with supplementary thoracoplasty. This combination was thought by Huang and Lyons ${ }^{18}$ to be particularly likely to cause cardiorespiratory failure. Nevertheless, we did not find any relationship of respiratory failure to the number of ribs resected or to combined pulmonary resection and thoracoplasty.

Some of the survivors seem perfectly well or have mild symptoms in which they may not differ from other people of their age. Most appear to have led normal lives in respect of capability for work, marriage, and child bearing, which were sometimes used to judge the success of a thoracoplasty in restoring patients to normality. ${ }^{2} 3$

The care of most patients with a thoracoplasty is now in the hands of their general practitioners. It is therefore of concern that replies to the questionnaires show that many have persisting symptoms of respiratory disease that they do not report to their general practitioner. Perhaps they have come to accept their chronic disability and believe that they cannot be helped. Many of them wheeze. This may be due to localised bronchostenosis or generalised bronchial narrowing from tuberculous endobronchitis, but some could have asthma and few are receiving treatment for this. Similarly, some of those who have not disclosed their ankle swelling to their general practitioner may be in heart failure and might benefit from diuretics. Many still smoke; our finding of less breathlessness among those who smoke may indicate that many patients, unless warned of the hazards, will give up smoking only when they become breathless. A few patients have symptoms that suggest chronic nocturnal hypoventilation.

The appropriate management of symptomatic chronic ventilatory failure in patients with a thoracoplasty includes assisted ventilation, best achieved by a device providing negative pressure ventilation. ${ }^{6}$ Often this need be used only intermittently, usually at night. For those patients who develop ventilatory failure acutely during some intercurrent illness such a device offers an acceptable alternative to intubation and positive pressure ventilation. There are grounds for considering that patients with a thoracoplasty should be seen at intervals by a physician with specia expertise in respiratory medicine, whose remit woulds? be not simply to exclude a recurrence of pulmonarye tuberculosis but to seek evidence of respiratory failure을 and anticipate any need for future ventilatory $\overline{\bar{\rho}}$ assistance.

We thank Dr JE Stark for his help in the preparation of this paper.

\section{References}

1 Keers RY. Pulmonary tuberculosis. A journey down theo centuries. London: Ballière Tindall, 1978:123-5; 168-74.

2 Francis RS, Curwen MP. Major surgery for pulmonary tuberculosis: final report. Tubercle 1964;45; suppl:1-79.

3 Sellors TH. The results of thoracoplasty in pulmonaryog tuberculosis. Thorax 1947;2:216-23.

4 Gough JH, Barlow D, Sellors TH, Thompson VC. The results of thoracoplasty in the treatment of pulmonary tuberculosis. Thorax 1957;12:241-52.

5 Sawicka EH, Branthwaite MA, Spencer GT. Respira-ฏ๊ tory failure after thoracoplasty: treatment by intermit-市 tent negative pressure ventilation. Thorax 1983;38: 433-5.

6 Kinnear WJM, Shneerson JM. Assisted ventilation at home: is it worth considering? Br J Dis Chest 1985; 79:313-51.

7 Office of Population, Censuses, and Surveys. Mortality statistics, serial tables. Review of the Registrar Generalo on deaths in England and Wales 1841-1980. London:@ HMSO, 1985. Table 2.

8 Peto R, Pike MC, Armitage P, et al. Design and analysis of randomised clinical trials requiring prolonged observation of each patient. II. Analysis and examples. Br J Cancer 1977;35:1-39.

9 Engelman L. Stepwise logistic regression. In: BMDPऽ statistical software manual. Los Angeles: University of California Press, 1985:14.5:330-40.

10 Caplin M, Griffiths JJ, Silver CP. Respiratory tuberculosis in East London. Tubercle 1956;37:233-42.

11 Gaensler EA, Cugell DW, Lundgren I, Smith SS, N Strieder JW. The role of pulmonary insufficiency in $N_{\mathcal{E}}$ mortality and invalidism following surgery for pul-o monary tuberculosis. J Thoracic Surg 1955;29:163-87.

12 Zimmerman HA. Hemodynamics: studies on a group of? patients who developed cor pulmonale following thoracoplasty. J Thoracic Surg 1951;22:94-8.

13 Cameron HM, McGoogan E. A prospective study of 1152 hospital autopsies: 1 . Inaccuracies in death certification. J Pathol 1981;133:273-83.

14 Loynes RD. Scoliosis after thoracoplasty. J Bone Joint Surg (Br) 1972;54:484-98.

15 Crofton J, Douglas A. Respiratory diseases. 3rd ed. Oxford: Blackwell Scientific Publications. 1981:268. 
16 Little GM. Loss of ventilatory function after surgical procedures for pulmonary tuberculosis. Tubercle 1956;37:172-6.

17 Gaensler EA, Strieder JW. Progressive changes in pulmonary function after pneumonectomy: the influence of thoracoplasty, pneumothorax, oleothorax and plas- tic sponge plombage on the side of pneumonectomy. $J$ Thorac Surg 1951;22:1-34.

18 Huang CT, Lyons HA. Cardiorespiratory failure in patients with pneumonectomy for pulmonary tuberculosis. Long term effects of thoracoplasty. J Thorac Cardiovasc Surg 1977;74:409-17. 